First publ. in: Journal of the American Chemical Society 130 (2008), 32, pp. 10748-10757

\title{
Opposed Steric Constraints in Human DNA Polymerase $\beta$ and E. coli DNA Polymerase I
}

\author{
Francesca Di Pasquale, ${ }^{\dagger}$ Daniela Fischer, ${ }^{\S}$ Dina Grohmann," Tobias Restle," \\ Armin Geyer, ${ }^{\ddagger}$ and Andreas Marx ${ }^{*} \dagger$ \\ Fachbereich Chemie, Universität Konstanz, Universitätsstrasse 10, D-78457 Konstanz, Germany, \\ Fachbereich Chemie, Hans Meerwein Strasse, Philipps-Universität Marburg, D-35032 Marburg, \\ Germany, Institut für Organische Chemie, Universitätsstrasse 31, Universität Regensburg, \\ D-93040 Regensburg, Germany, and Universitätsklinikum Schleswig-Holstein, Universität zu \\ Lübeck, Institut für Molekulare Medizin, Ratzeburger Allee 160, D-23538 Lübeck, Germany
}

E-mail: andreas.marx@uni-konstanz.de

\begin{abstract}
DNA polymerase selectivity is crucial for the survival of any living species, yet varies significantly among different DNA polymerases. Errors within DNA polymerase-catalyzed DNA synthesis result from the insertion of noncanonical nucleotides and extension of misaligned DNA substrates. The substrate binding characteristics among DNA polymerases are believed to vary in properties such as shape and tightness of the binding pocket, which might account for the observed differences in fidelity. Here, we employed 4'alkylated nucleotides and primer strands bearing $4^{\prime}$-alkylated nucleotides at the $3^{\prime}$-terminal position as steric probes to investigate differential active site properties of human DNA polymerase $\beta$ (Pol $\beta$ ) and the $3^{\prime} \rightarrow 5^{\prime}$-exonuclease-deficient Klenow fragment of $E$. coli DNA polymerase I (KF(exo-)). Transient kinetic measurements indicate that both enzymes vary significantly in active site tightness at both positions. While small 4'-methyl and -ethyl modifications of the nucleoside triphosphate perturb Pol $\beta$ catalysis, extension of modified primer strands is only marginally affected. Just the opposite was observed for KF(exo-). Here, incorporation of the modified nucleotides is only slightly reduced, whereas size augmentation of the 3'terminal nucleotide in the primer reduces the catalytic efficiency by more than 7000 - and 260000 -fold, respectively. NMR studies support the notion that the observed effects derive from enzyme substrate interactions rather than inherent properties of the modified substrates. These findings are consistent with the observed differential capability of the investigated DNA polymerases in fidelity such as processing misaligned DNA substrates. The results presented provide direct evidence for the involvement of varied steric effects among different DNA polymerases on their fidelity.
\end{abstract}

\section{Introduction}

DNA polymerases catalyze all DNA synthesis in nature including DNA replication, repair, and recombination. They are template-depending enzymes that transfer the information of the parental strand to the daughter strand. Selectivity according to Watson-Crick nucleobase pairing in this process is crucial for the preservation of the integrity of every species genome. High-fidelity DNA polymerases involved in DNA replication exhibit intrinsic error rates as low as one error (i.e., incorporation of a non-Watson-Crick paired nucleotide) within $10^{6}$ synthesized phosphodiester bonds. ${ }^{1}$ However, certain DNA polymerases that are involved in DNA repair exhibit strikingly low

\footnotetext{
¿ Universität Konstanz.

† Philipps-Universität Marburg.

$\S$ Universität Regensburg.

"Universität zu Lübeck.

(1) (a) Echols, H.; Goodman, M. F. Annu. Rev. Biochem. 1991, 60, 477511. (b) Kunkel, T. A.; Bebenek, K. Annu. Rev. Biochem. 2000, 69, 497-529. (c) Goodman, M. F. Annu. Rev. Biochem. 2002, 71, 17-50. (d) Kool, E. T. Annu. Rev. Biochem. 2002, 71, 191-219. (e) Kunkel, T. A. J. Biol. Chem. 2004, 279, 16859-16898. (f) Rothwell, P. J.; Waksman, G. Adv. Protein Chem. 2005, 71, 401-40. (g) McCulloch, S. D.; Kunkel, T. A. Cell Res. 2008, 18, 148-61.
}

fidelity when dealing with undamaged DNA. ${ }^{1,2}$ An understanding of the basis for the striking differences in fidelity among DNA polymerases is essential to understand the process of DNA replication. However, the mechanistic origins of DNA polymerase selectivity are still a matter of debate. ${ }^{3}$

Errors within DNA polymerase-catalyzed DNA synthesis result from the insertion of noncanonical nucleotides and its subsequent extension leading to single nucleotide substitutions. Various models for nucleotide substitution fidelity have been suggested to describe the mechanisms of DNA polymerases to select the canonical nucleotide during the insertion steps. ${ }^{1}$ At first glance, the formation of distinct hydrogen-bonding patterns between the nucleobases of the coding template strand and the incoming nucleoside triphosphate appears to be responsible for accurate nucleotide insertion. Yet, as suggested on the basis of thermal denaturating studies of matched and mismatched DNA complexes, these interactions alone are not sufficient to explain the extent of accuracy commonly observed for enzymatic DNA

(2) (a) Hübscher, U.; Maga, G.; Spadari, S. Annu. Rev. Biochem. 2002, 71, 133-163. (b) Prakash, S.; Johnson, R. E.; Prakash, L. Annu. Rev. Biochem. 2005, 74, 317-353.

(3) Kool, E. T.; Sintim, H. O. Chem. Commun. 2006, 35, 3665-3675. 
synthesis. ${ }^{1 \mathrm{a}, 4}$ Extensive studies indicate that for some DNA polymerases hydrogen bonding alone is not strictly required to achieve high incorporation efficiencies. ${ }^{1 \mathrm{~d}, 3}$ Close fitting of Watson-Crick geometry to the active site of the enzyme is cited as one of the most important factors for achieving selectivity in nucleotide insertion. However, DNA polymerase selectivity often varies significantly depending on the DNA polymerase. ${ }^{1 \mathrm{~d}, 2}$ The origin of this varying error propensity is elusive. Variations of active sites "openness" 5 as well as their "tightness" 1d,6,7 are cited as cause for observed different selectivity.

Besides the occurrence of errors during the nucleotide insertion step, DNA polymerases often generate errors by deletion of a nucleotide or insertion of an additional nucleotide resulting in frameshift mutations. ${ }^{1 \mathrm{~b}, \mathrm{e}, 8}$ The mechanisms that govern these errors are less well understood than those of nucleotide substitution fidelity despite the fact that frameshift mutations might exhibit severe biological consequences. ${ }^{8}$ Misalignment of the primer template complex is cited as reason for deletion and insertion errors. ${ }^{1 \mathrm{be}, \mathrm{e}} \mathrm{R}$ Recent studies have shown that strand misalignment fidelity depends on the DNA polymerase and varies more than 1000 -fold. ${ }^{8}$ For instance, human DNA polymerase $\beta$ ( $\mathrm{Pol} \beta$ ), a member of the DNA polymerase family $\mathrm{X}$, is much less accurate for single-nucleotide deletions than the $3^{\prime} \rightarrow 5^{\prime}$-exonuclease-deficient Klenow fragment of $E$. coli DNA polymerase I ( $\mathrm{KF}($ exo-) $)$, a member of the DNA polymerase family A. ${ }^{9}$ As functional ${ }^{10}$ and structural ${ }^{11}$ studies indicate, DNA polymerases form complex interactions with the primer template and nucleotide substrates during catalysis of DNA polymerization that may reach up to several nucleotide pairs beyond the active site. These interactions primarily occur

(4) Petruska, J.; Goodman, M. F.; Boosalis, M. S.; Sowers, L. C.; Cheong, C.; Tinoco, I., Jr Proc. Natl. Acad. Sci. U.S.A. 1988, 85, 6252-6256.

(5) (a) Silvian, L. F.; Toth, E. A.; Pham, P.; Goodman, M. F.; Ellenberger, T. Nat. Struct. Biol. 2001, 8, 984-989. (b) Trincao, J.; Johnson, R. E.; Escalante, C. R.; Prakash, S.; Prakash, L.; Aggarwal, A. K. Mol. Cells 2001, 8, 417-426. (c) Zhou, B. L.; Pata, J. D.; Steitz, T. A. Mol. Cells 2001, 8, 427-437. (d) Nair, D. T.; Johnson, R. E.; Prakash, S.; Prakash, L.; Aggarwal, A. K. Nature 2004, 430, 377-380. (e) Zang, H.; Goodenough, A. K.; Choi, J. Y.; Irimia, A.; Loukachevitch, L. V.; Kozekov, I. D.; Angel, K. C.; Rizzo, C. J.; Egli, M.; Guengerich, F. P. J. Biol. Chem. 2005, 280, 29750-29764. (f) Ling, H.; Boudsocq, F.; Woodgate, R.; Yang, W. Cell 2001, 107, 91-102. (g) Trincao, J.; Johnson, R. E.; Wolfle, W. T.; Escalante, C. R.; Prakash, S.; Prakash, L.; Aggarwal, A. K. Nat. Struct. Mol. Biol. 2004, 11, 457-462. (h) Ling, H.; Boudsocq, F.; Plosky, B. S.; Woodgate, R.; Yang, W. Nature 2003, 424, 1083-1087. (i) Ling, H.; Sayer, J. M.; Plosky, B. S.; Yagi, H.; Boudsocq, F.; Woodgate, R.; Jerina, D. M.; Yang, W. Proc. Natl. Acad. Sci. U.S.A. 2004, 101, 2265-2269.

(6) (a) Summerer, D.; Marx, A. Angew. Chem., Int. Ed. 2001, 40, 3693 3695. (b) Strerath, M.; Summerer, D.; Marx, A. ChemBioChem 2002, 3, 578-580. (c) Strerath, M.; Cramer, J.; Restle, T.; Marx, A. J. Am. Chem. Soc. 2002, 124, 11230-11231. (d) Cramer, J.; Strerath, M.; Marx, A.; Restle, T. J. Biol. Chem. 2002, 277, 43593-43598. (e) Cramer, J.; Rangam, G.; Marx, A.; Restle, T. ChemBioChem 2008, 9 , $1243-1250$.

(7) (a) Kim, T. W.; Delaney, J. C.; Essigmann, J. M.; Kool, E. T. Proc. Natl. Acad. Sci. U.S.A. 2005, 102, 15803-15808. (b) Mizukami, S.; Kim, T. W.; Helquist, S. A.; Kool, E. T. Biochemistry 2006, 45, 27722778. (c) Kim, T. W.; Brieba, L. G.; Ellenberger, T.; Kool, E. T. J. Biol. Chem. 2006, 281, 2289-2295. (d) Sintim, H. O.; Kool, E. T. J. Am. Chem. Soc. 2006, 128, 396-397. (e) Sintim, H. O.; Kool, E. T. Angew. Chem., Int. Ed. 2006, 45, 1974-1979. (f) Silverman, A. P.; Jiang, Q.; Goodman, M. F.; Kool, E. T. Biochemistry 2007, 46, 13874 13881 .

(8) Garcia-Diaz, M.; Kunkel, T. A. Trends Biochem. Sci. 2006, 31, 20614.

(9) (a) Kunkel, T. A. Biochemistry 1990, 29, 8003-8011. (b) Bebenek, K.; Joyce, C. M.; Fitzgerald, M. P.; Kunkel, T. A. J. Biol. Chem. 1990, 265, 13878-13887. (c) Osheroff, W. P.; Jung, H. K.; Beard, W. A.; Wilson, S. H.; Kunkel, T. A. J. Biol. Chem. 1999, 274, 3642 3650 . through the minor groove of the DNA duplex with the sugar-phosphodiester backbone and the nucleobases of the primer template complex. Structural studies indicate that $\mathrm{Pol} \beta$ undergoes fewer contacts with the DNA primer template duplex upstream of the active site compared to KF(exo-). ${ }^{1 \mathrm{~b}, 12}$ These findings suggest that enzyme contacts with the primer template strands are crucial for misalignment fidelity. An enzyme exhibiting high misalignment fidelity might form tighter primer template binding pockets tolerating less geometric deviation (e.g., misaligned primer template complexes) and thereby preventing frameshift mutations resulting from nucleotide deletions and insertions, while low fidelity enzymes exhibit more flexibility leading to decreased fidelity. Indeed, recent studies of DNA polymerase $\lambda$, an enzyme belonging to the same family as Pol $\beta$ that has a high single-base deletion error rate, have been shown to be sufficiently flexible to accommodate even an extrahelical nucleotide within the misaligned primer template complex. $^{13}$

Recently, functional means to investigate steric constraints like "tightness" in DNA polymerases have been developed and yielded new insights into their function. Kool et al. have employed gradually expanding thymidine analogues to investigate tightness and polar effects within the active site acting on the nucleobase. ${ }^{7}$ They used nonpolar nucleobase surrogates with a limited ability to form hydrogen bonds. Moreover, the size of these compounds increased incrementally by use of halogen atoms substituting the oxygen atoms of thymidine. We have developed and utilized 4'-alkyl-modified nucleotides, which continually increase in steric bulk for probing steric effects in DNA polymerase function acting on the deoxyribose. ${ }^{6,10 f, g}$ Alkyl groups were employed because potential effects on hydrogenbonding patterns and conformations of the nucleotides on DNA polymerase function are minimized. Both approaches suggest an important contribution of steric effects on DNA polymerase selectivity and variations thereof to be involved in varied selectivity among different enzymes.

To better understand the fundamentals of markedly varied properties of DNA polymerases like Pol $\beta$ and $\mathrm{KF}$ (exo-) (vide supra), we investigated the tightness of contacts of these

(10) (a) Carver, T. E., Jr.; Hochstrasser, R. A.; Millar, D. P. Proc. Natl. Acad. Sci. U.S.A. 1994, 91, 10670-10674. (b) Morales, J. C.; Kool, E. T. J. Am. Chem. Soc. 1999, 121, 2323-2324. (c) Morales, J. C.; Kool, E. T. Biochemistry 2000, 39, 12979. (d) Spratt, T. E. Biochemistry 2001, 40, 2647-2652. (e) Thompson, E. H. Z.; Bailey, M. F.; van der Schans, E. J. C.; Joyce, C. M.; Millar, D. P. Biochemistry 2002, 41, 713-722. (f) Summerer, D.; Marx, A. J. Am. Chem. Soc. 2002, 124, 910-911. (g) Strerath, M.; Gaster, J.; Marx, A. ChemBioChem 2004, 5, 1585-1588.

(11) For example:(a) Pelletier, H.; Sawaya, M. R.; Kumar, A.; Wilson, S. H.; Kraut, J. Science 1994, 264, 1891-1903. (b) Doublié, S.; Tabor, S.; Long, A. M.; Richardson, C. C.; Ellenberger, T. Nature 1998, 391, 251-258. (c) Li, Y.; Korolev, S.; Waksman, G. EMBO J. 1998, 17, 7514-7525. (d) Kiefer, J. R.; Mao, C.; Braman, J. C.; Beese, L. S. Nature 1998, 391, 304-307. (e) Huang, H. F.; Chopra, R.; Verdine, G. L.; Harrison, S. C. Science 1998, 282, 1669-1675. (f) Franklin, M. C.; Wang, J.; Steitz, T. A. Cell 2001, 105, 657-667. (g) Johnson, S. J.; Taylor, J. S.; Beese, L. S. Proc. Natl. Acad. Sci. U.S.A. 2003, 100, 3895-3900. (h) Johnson, S. J.; Beese, L. S. Cell 2004, 116, 803816. (i) Kamtekar, S.; Berman, A. J.; Wang, J.; Lázaro, J. M.; de Vega, M.; Blanco, L.; Salas, M.; Steitz, T. A. EMBO J. 2006, 25, 1335-1343. (j) Berman, A. J.; Kamtekar, S.; Goodman, J. L.; Lázaro, J. M.; de Vega, M.; Blanco, L.; Salas, M.; Steitz, T. A. EMBO J. 2007, 26, 3494-3505.

(12) Beard, W. A.; Wilson, S. H. Chem. Rev. 2006, 106, 361-382.

(13) (a) Garcia-Diaz, M.; Bebenek, K; Krahn, J. M.; Pedersen, L. C.; Kunkel, T. A. Cell 2006, 124, 331-342. (b) Bebenek, K.; GarciaDiaz, M.; Foley, M. C.; Pedersen, L. C.; Schlick, T.; Kunkel, T. A. EMBO Rep. 2008, 9, 459-64. 
enzymes with their substrates. We employed 4'-alkylated nucleotides and oligonucleotides as steric probes and compared active site constraints acting on the nucleoside triphosphate as well as on the primer template of the respective enzyme. Depending on the position of the steric probe (incoming nucleotide or 3 -end of the primer strand) and the enzyme studied, drastically different effects concerning nucleotide incorporation were observed. Comparative NMR investigations of 4'-modified oligonucleotides and nonmodified counterparts indicated no significant effect of the modification on DNA conformation and duplex formation. Thus, this finding supports the notion that the observed effects derive from size augmentation of the substrate rather than the formation of aberrant substrate conformations. Our findings strongly indicate that indeed these varied size constraints are accountable for the observed differences in substrate recognition accuracy of $\operatorname{Pol} \beta$ and $\mathrm{KF}$ (exo-).

\section{Materials and Methods}

Purification of Recombinant DNA Polymerases. A $3^{\prime}-5^{\prime}-$ exonuclease-deficient variant of the Klenow Fragment of $E$. coli DNA polymerase I and human DNA polymerase $\beta$ were expressed and purified as described. ${ }^{14}$ The purity of the proteins was $>95 \%$ as controlled by SDS-PAGE. The concentrations were determined by the Bradford assay.

Nucleoside Triphosphates and DNA Substrates. 4'-Modified nucleoside triphosphates and oligonucleotides were synthesized and purified as described. ${ }^{6,10 \mathrm{f}, \mathrm{g}}$ Unmodified dNTPs were purchased from Roche. Unmodified oligonucleotides were purchased from IBA, Göttingen. Employed sequences: primer 24merA, 5'-d(GTG GTG CGA AAT TTC TGA CAG ACA); primer 25 merT $^{\mathrm{R}}, 5^{\prime}$-d(GTG GTG CGA AAT TTC TGA CAG ACA $\mathbf{T}^{\mathbf{R}}, \mathrm{R}: \mathbf{H}=4^{\prime}-\mathrm{H}, \mathbf{M e}=$ $4^{\prime}-\mathrm{CH}_{3}, \mathbf{E t}=4^{\prime}-\mathrm{CH}_{2} \mathrm{CH}_{3}$; template 36 mer, $5^{\prime}$-d(GTG CGT CTG TCA TGT CTG TCA GAA ATT TCG CAC CAC). The primer strands were radiolabeled using $\gamma-\left[{ }^{32} \mathrm{P}\right]-\mathrm{ATP}$ and T4 polynucleotide kinase (Fermentas) according to standard protocols.

Primer Extension Studies. Pol $\beta$ reactions contained $40 \mathrm{nM}$ primer template and $40 \mathrm{nM}$ enzyme in $50 \mathrm{mM}$ TrisHCl $\mathrm{pH} 8.0,10$ $\mathrm{mM} \mathrm{MgCl} 2,2 \mathrm{mM}$ DTT, $20 \mathrm{mM} \mathrm{NaCl}, 20 \mathrm{mM} \mathrm{KCl}, 200 \mu \mathrm{g} / \mathrm{mL}$ BSA, glycerol $1 \%^{15}$ in a final volume of $20 \mu \mathrm{L}$ and dNTPs at the concentrations indicated in the corresponding figures. $\mathrm{KF}$ (exo-) reaction mixtures consisted of $40 \mathrm{nM}$ primer template and $2 \mathrm{nM}$ enzyme in $50 \mathrm{mM}$ TrisHCl pH 7.3, $10 \mathrm{mM} \mathrm{MgCl}_{2}, 1 \mathrm{mM} \mathrm{DTT}^{6 \mathrm{a}}$ in a final volume of $20 \mu \mathrm{L}$ and dNTPs at the concentrations indicated in the corresponding figures. The reaction mixtures were incubated for $20 \mathrm{~min}$ at $37{ }^{\circ} \mathrm{C}$ and subsequently quenched using PAGE loading solution $(80 \%[\mathrm{v} / \mathrm{v}]$ formamide, $20 \mathrm{mM}$ EDTA, $0.025 \%[\mathrm{w} / \mathrm{v}]$ bromophenol blue, $0.025 \%$ [w/v] xylene cyanol) and analyzed by $12 \%$ PAGE containing $8 \mathrm{M}$ urea. Visualization was performed using phosphorimaging.

Kinetics. The rate of single turnover, single nucleotide incorporation was determined using the different primer/36mer template DNA duplexes performing presteady-state measurements. Rapidquench assays were carried out using a KinTek RQF-3 rapid quench flow apparatus (KinTek Corp., Austin, TX). Pol $\beta$ reaction mixtures contained $100 \mathrm{nM}$ primer template, $1 \mu \mathrm{M}$ enzyme, and different concentrations of dNTP in reaction buffer. $\mathrm{KF}$ (exo-) reaction mixtures consisted of $100 \mathrm{nM}$ primer template, $200 \mathrm{nM}$ enzyme, and different concentrations of dNTP in reaction buffer. The reaction was initiated by mixing equal volumes ( $15 \mu \mathrm{L}$ each) of a solution containing enzyme and DNA primer template substrate with a solution containing the $\mathrm{dNTP}(0.1 \mu \mathrm{M}-1 \mathrm{mM})$ in reaction buffer

(14) (a) Summerer, D.; Rudinger, N. Z.; Detmer, I.; Marx, A. Angew. Chem., Int. Ed. 2005, 44, 4712-4715. (b) Kosa, J. L.; Sweasy, J. B. J. Biol. Chem. 1999, 274, 3851-3858.

(15) Tae, E. L.; Wu, Y.; Xia, G.; Schultz, P. G.; Romesberg, F. E. J. Am Chem. Soc. 2001, 123, 7439-40.
For reaction times ranging from 0.05 to $10 \mathrm{~s}$, the rapid quench instrument was used. The reactions were quenched using $0.6 \% \mathrm{TFA}$ prior to mixing with a PAGE loading solution $(80 \%[\mathrm{v} / \mathrm{v}]$ formamide, $0.025 \%$ [w/v] bromophenol blue, $0.025 \%$ [w/v] xylene cyanol). For reaction times longer than $10 \mathrm{~s}$, a manual quench was performed. Samples of the quenched reactions were denatured at $95^{\circ} \mathrm{C}$ for $5 \mathrm{~min}$ and analyzed by $12 \%$ PAGE containing $8 \mathrm{M}$ urea. Visualization was carried out by phosphorimaging. The product bands were quantified using the BioRad Quantity One software. For presteady-state analysis, experimental data were fit by nonlinear regression using the program GraphPad Prism 4. The data were fit to a single exponential equation: [Primer +1$]=A^{*}(1-$ $\left.\exp \left(-k_{\mathrm{obs}} t\right)\right)$. The observed catalytic rates $\left(k_{\mathrm{obs}}\right)$ were then plotted against the dNTP concentration used, and the data were fitted to a hyperbolic equation to determine the $K_{\mathrm{d}}$ of the incoming nucleotide. The incorporation efficiency is given by $k_{\mathrm{pol}} / K_{\mathrm{d}}$. The kinetic data result from multiple independently conducted experiments (duplicates or triplicates).

NMR Studies. The signal assignment for the tetramers dACAT (4PH) $\left(1.6 \mathrm{mg}, n=1.09 \times 10^{-6} \mathrm{~mol}, c=1.66 \mathrm{mM}\right), \mathrm{dACAT}^{\mathrm{Me}}$ (4PM) (1.84 mg, $\left.n=1.25 \times 10^{-6} \mathrm{~mol}, c=1.79 \mathrm{mM}\right)$, and dATGT (4T) $\left(3.42 \mathrm{mg}, n=2.29 \times 10^{-6} \mathrm{~mol}, c=3.27 \mathrm{mM}\right)$ were performed as triethylammonium salts at $300 \mathrm{~K}$ in $0.7 \mathrm{~mL}$ in phosphate buffer (30 mM, pH 7, $\left.\mathrm{D}_{2} \mathrm{O}\right)$. The double strands 4PM/ 4T and 4PH/4T were obtained by adding $4 \mathrm{~T}$ to the NMR tubes containing 4PM $(455 \mu \mathrm{L}$ of $\mathbf{4 T}$, molar ratio $\mathbf{4 P H}: 4 \mathbf{T}=0.95)$ and 4PH $(515 \mu \mathrm{L}$, molar ratio 4PM:4T $=0.96)$, respectively. All measurements were performed on a Bruker Avance DRX 600 spectrometer with a $5 \mathrm{~mm}$ BBI probe head. Homonuclear 2D spectra (TOCSY, ROESY) were recorded at $320 \mathrm{~K}$ in the phase-sensitive mode as data matrices of $512\left(t_{1}\right)$ real $\times 2048\left(t_{2}\right)$ complex data points; 48 scans (TOCSY) and 80 scans, respectively, were used per $t_{1}$ increment. The used spectral widths were between 6602 and $9014 \mathrm{~Hz}$. Mixing times of $100 \mathrm{~ms}$ (TOCSY) and $150 \mathrm{~ms}$ (ROESY) were applied. Heteronuclear 2D HSQC experiments were performed in the phase-sensitive mode with data matrices of $512\left(t_{1},{ }^{13} \mathrm{C}\right)$ real $\times 2048\left(t_{2},{ }^{1} \mathrm{H}\right)$ complex data points and 80 scans per $t_{1}$ increment. All data were recorded and analyzed using Bruker TopSpin software. This chemical shift is calibrated on sodium 3-(trimethylsilyl)propionic acid $\left(\delta=0.00 \mathrm{ppm},{ }^{1} \mathrm{H}\right)$ and acetate as internal references $\left(\delta=21.03 \mathrm{ppm},{ }^{13} \mathrm{C}\right)$, respectively.

\section{Results}

Primer Extension by Pol $\boldsymbol{\beta}$ and KF(exo-). To probe the active sites and primer contacts of $\mathrm{Pol} \beta$ and $\mathrm{KF}$ (exo-), we performed single nucleotide incorporation studies employing a radiometric assay (Figure 1). First, we investigated incorporation of thymidine and the size augmented steric probes derived by substitution of the 4'-hydrogen atom with methyl and ethyl, respectively. Under the chosen conditions, Pol $\beta$ did not incorporate size augmented thymidine analogues, while the unmodified TTP was processed (Figure 1C). In contrast, $\mathrm{KF}$ (exo-) accepted the steric probes, and primer extension was observed in all cases (Figure 1C). However, when primer extension from the size augmented nucleotides placed at the 3 '-terminal nucleotide in the primer strand was investigated, opposed results were observed for both enzymes (Figure 1D). Pol $\beta$ was able to extend $4^{\prime}$-alkylated primer strands to a certain extent, while $\mathrm{KF}$ (exo-) was unable to synthesize significant amounts of extension products. These observations indicate that significantly different steric constraints act on the incoming nucleotide and the primer strand of the two polymerases, which were quantified as described in the following.

Quantitative Studies of $\operatorname{Pol} \boldsymbol{\beta}$. To characterize the active site tightness of Pol $\beta$ in more detail, we measured nucleotide incorporation under presteady-state conditions using a quench flow device. Kinetic experiments were performed by examining 
A

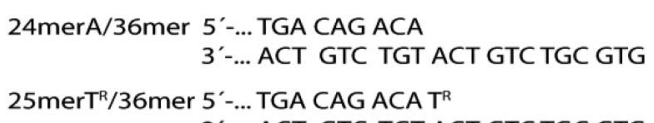

3'-... ACT GTC TGT ACT GTC TGC GTG
B

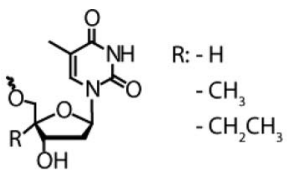

C Pol B

$24 n t$

$\mathrm{T}^{\mathrm{R} T P}$

$\mathrm{R}$ :

D

Pol B

$25 n t$

dGTP

25merT ${ }^{\mathrm{R}}$ :
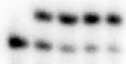

0105050

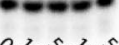

0105050

$\mathrm{Me}$

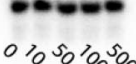

Et

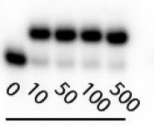

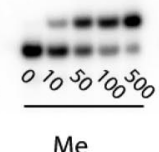

Me
KF (exo-)

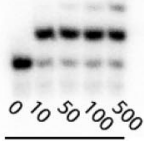

$\mathrm{H}$
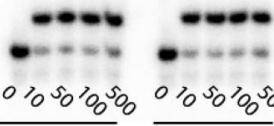

$010^{5} \%_{0} \mathrm{SO}_{0} \mu \mathrm{M}$

$\mathrm{Me}$

Et

Figure 1. Effects of $4^{\prime}$-alkyl groups on Pol $\beta$ and KF(exo-) promoted nucleotide insertion. (A) Partial DNA sequences and (B) thymidine analogues used in this study. (C) Effects on incoming nucleotide. (D) Effects on $3^{\prime}$-terminal position in primer strand; dNTP concentrations are indicated in the figure. Reactions performed at $37^{\circ} \mathrm{C}$ for 20 min equally contained $\mathrm{Pol} \beta$ or $\mathrm{KF}$ (exo-) and primer template complex.
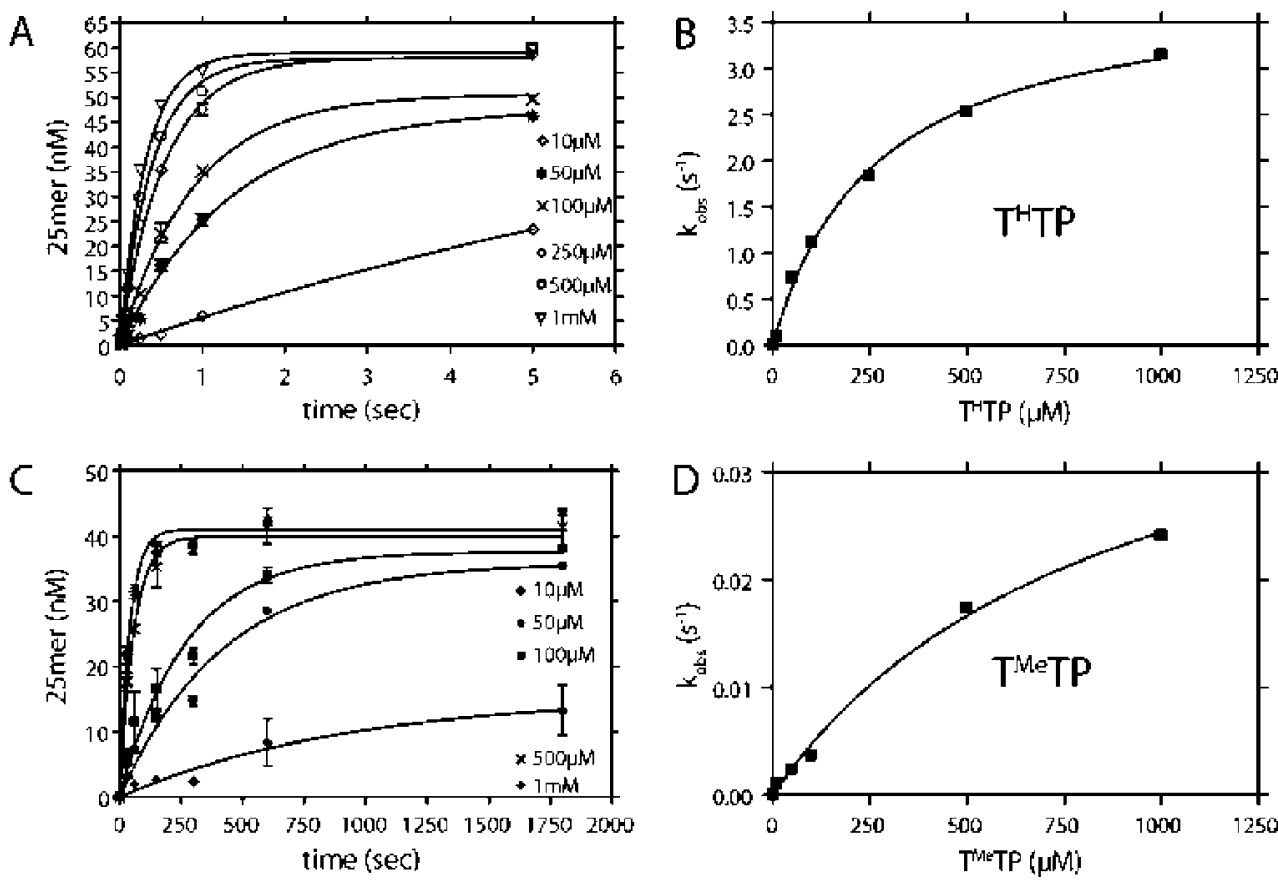

Figure 2. Presteady-state kinetics of $\mathrm{T}^{\mathrm{H}} \mathrm{TP}$ and $\mathrm{T}^{\mathrm{Me}} \mathrm{TP}$ incorporation into $24 \mathrm{mer} / 36 \mathrm{mer}$ primer template complex (100 nM) by Pol $\beta$ ( $1 \mu \mathrm{M}$ ). (A and C) Product versus time plot. The curves show the best fit of the data to a single exponential equation. A preformed complex of Pol $\beta$ and primer template was rapidly mixed with different concentrations of $\mathrm{T}^{\mathrm{H}} \mathrm{TP}(\mathrm{A})$ or $\mathrm{T}^{\mathrm{Me}} \mathrm{TP}(\mathrm{C})$ as indicated in the figure. (B and $\left.\mathrm{D}\right)$ Dependence of the presteady-state rates on the $\mathrm{T}^{\mathrm{H}} \mathrm{TP}(\mathrm{B})$ or $\mathrm{T}^{\mathrm{Me}} \mathrm{TP}(\mathrm{D})$ concentration. The $k_{\mathrm{obs}}$ values were plotted versus the $\mathrm{T}^{\mathrm{R}} \mathrm{TP}$ concentration and fitted to a hyperbolic equation.

single nucleotide extensions of a 24 mer primer annealed to a 36 mer template using an excess of enzyme over DNA substrate (Figure 2). The resulting values of $k_{\mathrm{pol}}$, that is, effective presteady-state nucleotide incorporation rate, $K_{\mathrm{d}}$, which is the affinity of the binary polymerase/primer template complex for the incoming nucleotide, and the incorporation efficiency $\left(k_{\mathrm{pol}} /\right.$ $K_{\mathrm{d}}$ ) are listed in Table 1 . For the unmodified $\mathrm{T}^{\mathrm{H}} \mathrm{TP}$, a $K_{\mathrm{d}}$ of $264 \pm 24 \mu \mathrm{M}$ and a polymerization rate of $3.9 \pm 0.1 \mathrm{~s}^{-1}$ were found. These results are in the same order as recently published data obtained in a different sequence context. ${ }^{16}$ Binding of

(16) Werneburg, B. G.; Ahn, J.; Zhong, X.; Hondal, R. J.; Kraynov, V. S.; Tsai, M. D. Biochemistry 1996, 35, 7041-50.
$\mathrm{T}^{\mathrm{Me}} \mathrm{TP}$ was about 3-fold weaker as compared to the unmodified substrate, and the incorporation rate dropped about 100-fold. Together, this yielded a 280-fold decrease of nucleotide incorporation efficiency through size augmentation by a methylene group. Further increasing the size of the modified substrate by an ethyl group was not tolerated by $\operatorname{Pol} \beta$, and nucleotide insertion was not observed even at high concentrations of $\mathrm{T}^{\mathrm{Et}} \mathrm{TP}$ (up to $2 \mathrm{mM}$ ). To determine possible steric constraints acting on the primer strand, the 3 '-end of the primer was modified with a $\mathrm{T}^{\mathrm{R}} \mathrm{MP}$ residue and elongation by $\operatorname{Pol} \beta$ was analyzed. For this endeavor, we used a 25 mer primer strand annealed to a 36mer template used before. Primer extension by incorporation 
Table 1. Kinetic Parameters for the Incorporation of $T^{\mathrm{R}} \mathrm{TP}$ Using a 24nt Primer 36 nt Template ${ }^{a}$

\begin{tabular}{|c|c|c|c|c|c|c|}
\hline & \multicolumn{2}{|c|}{$K_{\mathrm{d}}(u \mathrm{M})$} & \multicolumn{2}{|c|}{$k_{\text {pol }}\left(\mathrm{s}^{-1}\right)$} & \multicolumn{2}{|c|}{$k_{\mathrm{po}} / K_{\mathrm{d}}\left(\mathrm{M}^{-1} \mathrm{~s}^{-1}\right)$} \\
\hline & Pol $\beta$ & KF(exo-) & Pol $\beta$ & $\mathrm{KF}(\mathrm{exo}-)$ & Pol $\beta$ & KF(exo-) \\
\hline $\mathrm{R}=\mathrm{H}$ & $264 \pm 24$ & $33 \pm 1.0$ & $3.9 \pm 0.1$ & $230 \pm 13$ & 15000 & 7000000 \\
\hline
\end{tabular}

${ }^{a}$ n.a., not accessible.

A

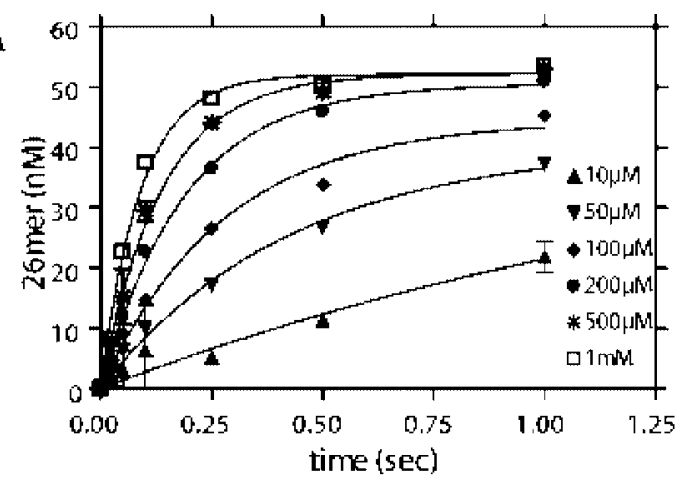

$\mathrm{C}$

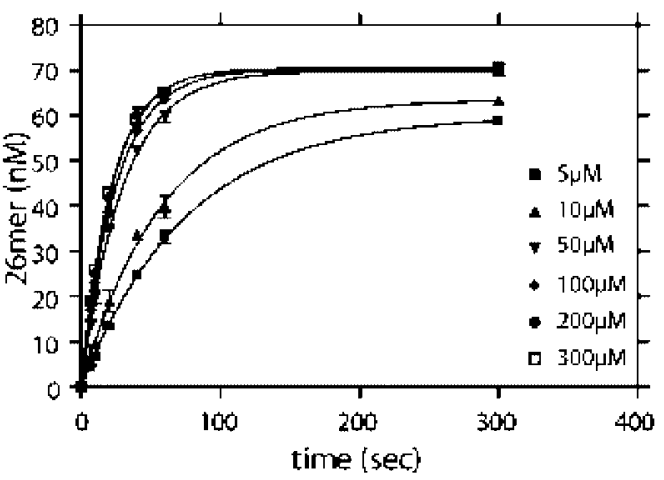

$\mathrm{E}$

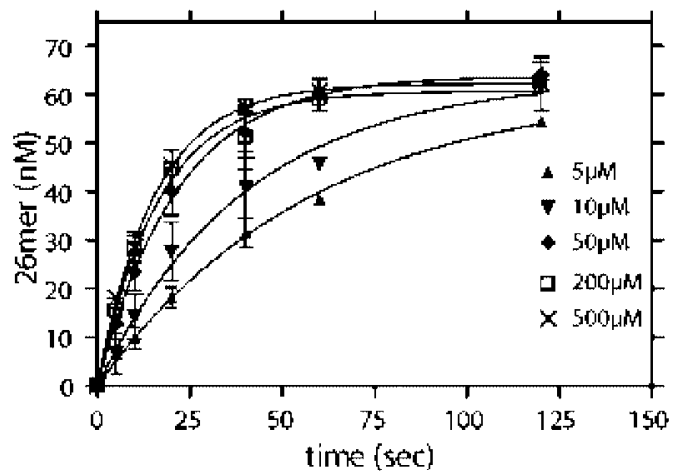

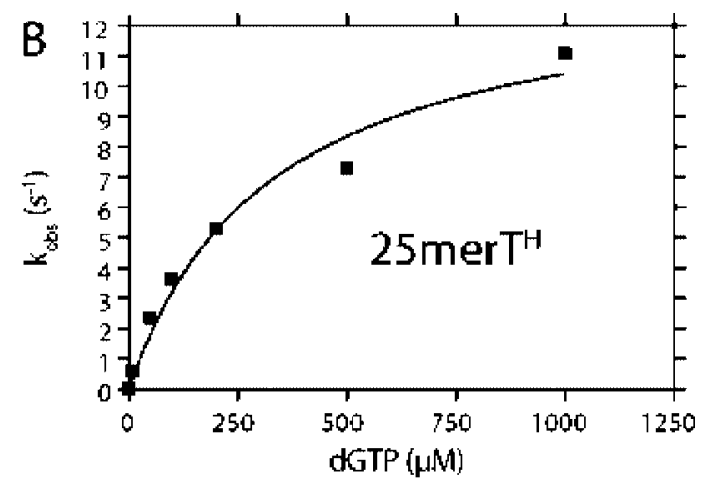
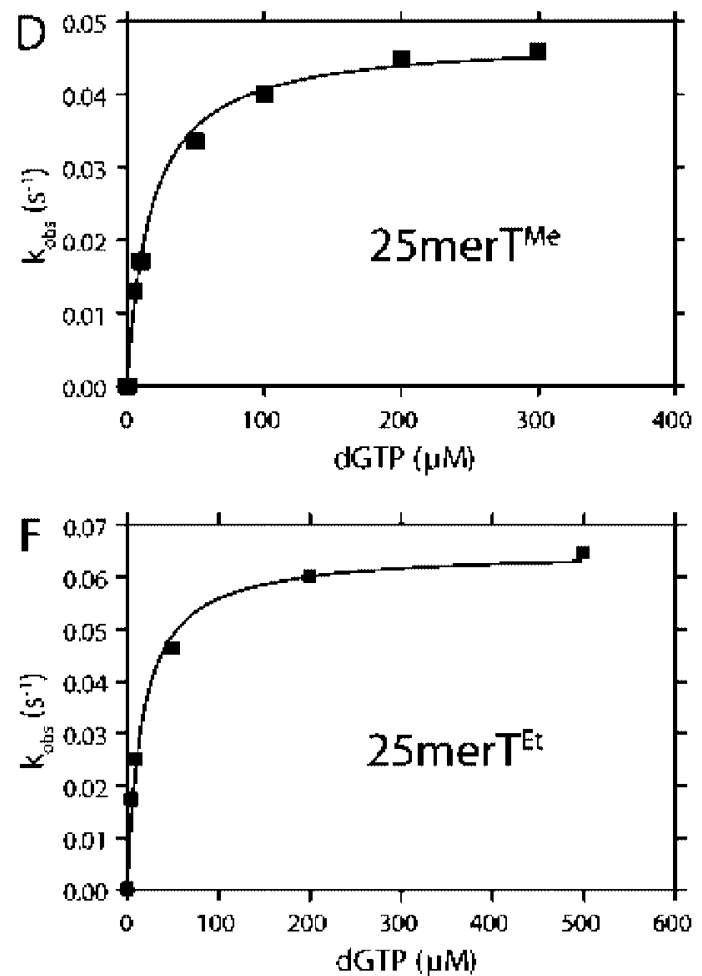

Figure 3. Presteady-state kinetics of single nucleotide (dG) extension of a 25 merT $^{\mathrm{R}} / 36$ mer primer template complexes $(100 \mathrm{nM})$ by Pol $\beta(1 \mu \mathrm{M})$. (A,C,E) Product versus time plots. The curves show the best fit of the data to a single exponential equation. A preformed complex of Pol $\beta$ and $25 \mathrm{merT} \mathrm{T}^{\mathrm{R}} / 36 \mathrm{mer}$ primer template was rapidly mixed with different concentrations of dGTP as indicated in the figure. (B,D,F) Dependence of the observed presteady-state rates on dGTP concentration. The $k_{\mathrm{obs}}$ values were plotted versus the concentration of dGTP and fitted to a hyperbolic equation.

Table 2. Kinetic Parameters for the Incorporation of dGTP Using $4^{\prime}$-Alkylated 25 merT $^{\mathrm{R}}$ Primer $36 \mathrm{mer}$ Template

\begin{tabular}{|c|c|c|c|c|c|c|}
\hline & $\begin{array}{c}K_{\mathrm{d}}(\mu \mathrm{M}) \\
\mathrm{Pol} \beta\end{array}$ & KF(exo-) & $\begin{array}{l}k_{\text {pol }}\left(\mathrm{s}^{-1}\right) \\
\mathrm{Pol} \beta\end{array}$ & KF(exo-) & $\begin{array}{c}k_{\text {pol }} / K_{d}\left(M^{-1} \mathrm{~s}^{-1}\right) \\
\operatorname{Pol} \beta\end{array}$ & KF(exo-) \\
\hline 25 merT $^{\mathrm{H}}$ & $328 \pm 85$ & $1.6 \pm 0.2^{a}$ & $13.8 \pm 1.5$ & $20.0 \pm 0.3^{a}$ & 42000 & $12000000^{a}$ \\
\hline $25 \mathrm{merT}^{\mathrm{Me}}$ & $17.3 \pm 2.3$ & $10.2 \pm 1.8$ & $0.048 \pm 0.001$ & $0.017 \pm 0.001$ & 2800 & 1700 \\
\hline
\end{tabular}

${ }^{a}$ Reaction performed at $22^{\circ} \mathrm{C}$.

of a canonical dGTP opposite a $\mathrm{dC}$ in the template was investigated (Figure 3, Table 2). Pol $\beta$ showed a $K_{\mathrm{d}}$ of $328 \pm$ $85 \mu \mathrm{M}$ for dGTP and an incorporation rate of $13.8 \pm 1.5 \mathrm{~s}^{-1}$ when an unmodified primer template complex was used. Primer extension was hampered by $4^{\prime}$-alkylation and decreased about 15 -fold when extending from $25 \mathrm{merT}^{\mathrm{Me}}$ and 10 -fold from 

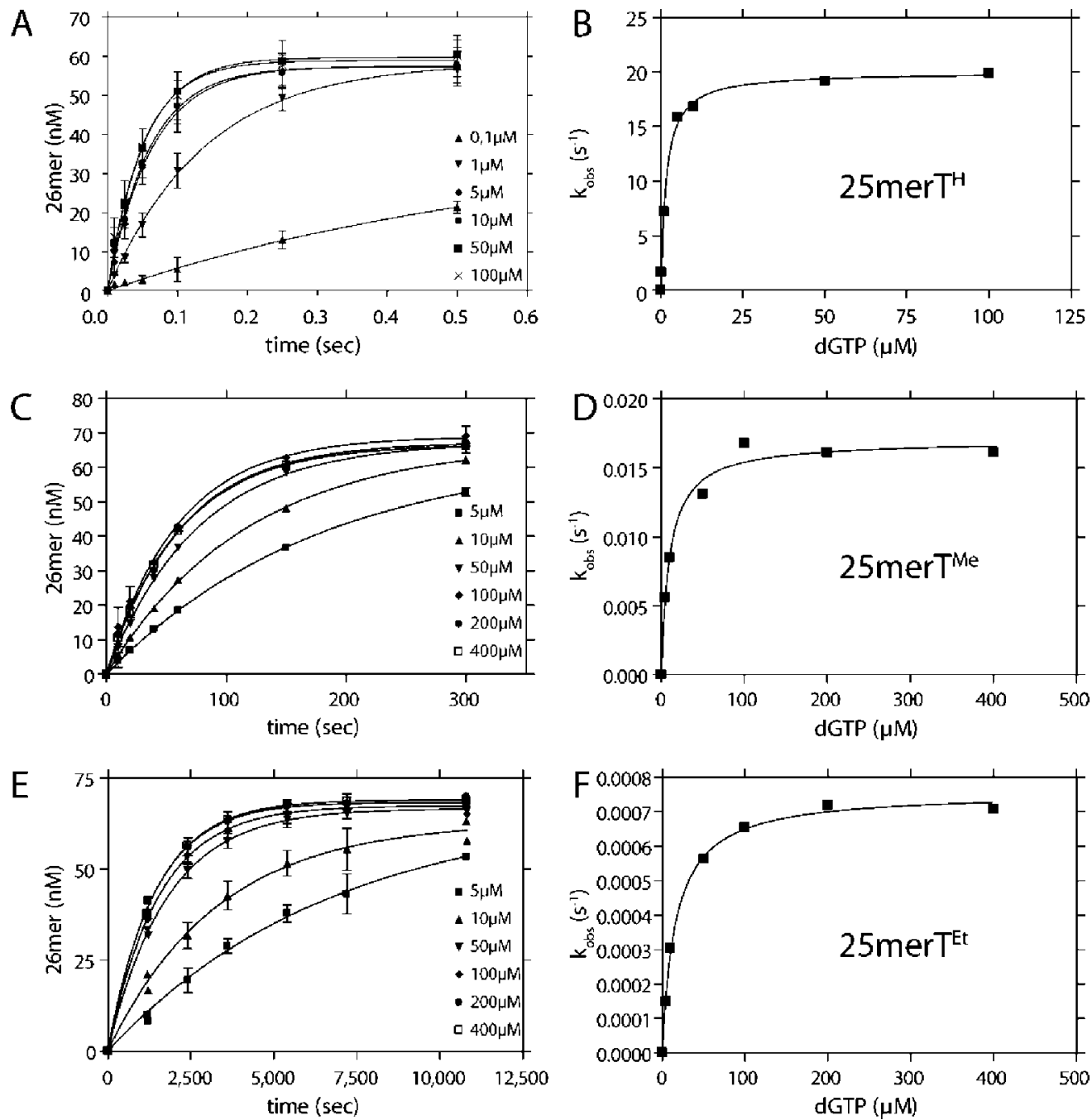

Figure 4. Presteady-state kinetics of single nucleotide (dG) extension of a $25 \mathrm{merT}^{\mathrm{R}} / 36$ mer primer template complexes (100 $\left.\mathrm{nM}\right)$ by $\mathrm{KF}(\mathrm{exo}-)$ (200 $\left.\mathrm{nM}\right)$. $(\mathrm{A}, \mathrm{C}, \mathrm{E})$ Product versus time plots. The curves show the best fit of the data to a single exponential equation. A preformed complex of KF(exo-) and $25 \mathrm{merT} \mathrm{R}^{\mathrm{f}}$ 36mer primer template was rapidly mixed with different concentrations of dGTP as indicated in the figure. (B,D,F) Dependence of the observed presteadystate rates on dGTP concentration. The $k_{\mathrm{obs}}$ values were plotted versus the concentration of dGTP and fitted to a hyperbolic equation.

$25 m e r T^{E t}$. Albeit size augmentation at the primer through $4^{\prime}$ alkylation of the terminal nucleotide had effects on extension efficiency of Pol $\beta$, the observed effects of the modifications are less pronounced as compared to the effects of steric constraints acting on the incoming nucleotide.

Quantitative Studies of KF(exo-). As we reported recently, ${ }^{6 e}$ $\mathrm{KF}($ exo-) showed a higher incorporation efficiency using steric augmented analogues of $\mathrm{T}^{\mathrm{H}} \mathrm{TP}$ as compared to Pol $\beta$ (Table 1). However, as shown in the present study, elongation of primers bearing a modified $\mathrm{T}^{\mathrm{R}} \mathrm{MP}$ at the $3^{\prime}$-end was significantly affected. While the recently reported $\mathrm{T}^{\mathrm{R}} \mathrm{TP}$ incorporation studies were conducted employing transient kinetics, ${ }^{6 e}$ extension studies from modified primer strands shown in Figure 1 were performed by steady-state kinetic analysis. ${ }^{10 f}$ To directly compare the Pol $\beta$ data with $\mathrm{KF}$ (exo-) data, we additionally did a transient kinetic analysis of $\mathrm{KF}$ (exo-), performing extension studies from $3^{\prime}$ terminal nonmodified and $4^{\prime}$-modified primers using the same oligonucleotide sequences as before. Our results employing unmodified substrates are within the same order as recently published data obtained in a different sequence context, ${ }^{17}$ whereas the affinity of a binary complex of $\mathrm{KF}\left(\mathrm{exo}^{-}\right)$and the $4^{\prime}$-modified primer template complex for dGTP decreased by a factor of 10 (Figure 4, Table 2). Most interestingly, a dramatic drop in nucleotide incorporation rates was observed with the $4^{\prime}$-methyl-substituted primer. Here, the polymerization rate of the enzyme dropped more than 1000-fold and for the $4^{\prime}$-ethylsubstituted primer more than 26000 -fold. This resulted in 7000 and 260000 -fold declines of extension efficiency, respectively. Taken together, $\mathrm{KF}$ (exo-) is significantly more sensitive to $4^{\prime}$ alkyl modifications at the primer strand and thus exhibits an opposed behavior to $\operatorname{Pol} \beta$ (Figure 5).

NMR Studies. The observed effects might well derive from aberrant oligonucleotide conformations at the primer end caused by the $4^{\prime}$-modifications. Up to now, 4'-modified oligonucleotides were investigated by employment of CD spectroscopy. ${ }^{18}$ To gain more insights in whether $4^{\prime}$-modifications at the $3^{\prime}$-primer end might have an effect on the DNA conformation, we performed NMR studies. Because ${ }^{1} \mathrm{H}$ chemical shifts, $J$-couplings, and NOEs are sensitive to variations of DNA conformational

(17) (a) Kuchta, R. D.; Mizrahi, V.; Benkovic, P. A.; Johnson, K. A.; Benkovic, S. J. Biochemistry 1987, 26, 8410-8417. (b) Lowe, L. G.; Guengerich, F. P. Biochemistry 1996, 35, 9840-9849. (c) Astatke, M.; Grindley, N. D.; Joyce, C. M. J. Mol. Biol. 1998, 278, 147-165.

(18) (a) Detmer, I.; Summerer, D.; Marx, A. Eur. J. Org. Chem. 2003, 1837-1846. (b) Detmer, I.; Summerer, D.; Marx, A. Chem. Commun. 2002, 2314-2315. 

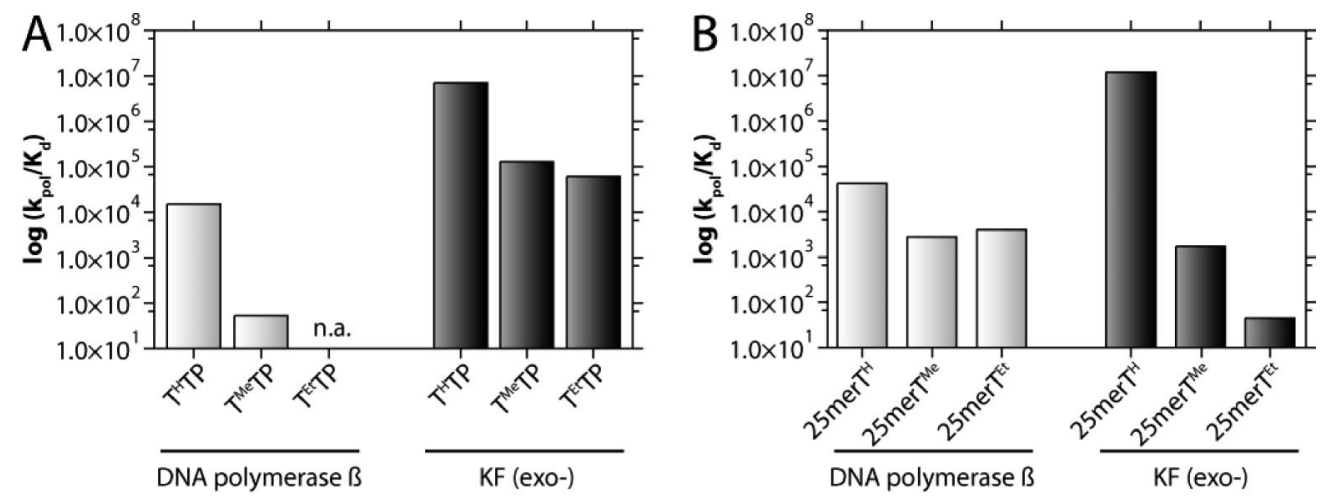

Figure 5. (A) Representation of the incorporation efficiencies of $\mathrm{T}^{\mathrm{R}} \mathrm{TP}$ into a $24 \mathrm{nt} / 36 \mathrm{nt}$ primer template by Pol $\beta$ and $\mathrm{KF}$ (exo-). (B) Representation of the incorporation efficiencies of dGTP into $4^{\prime}$-alkylated $25 \mathrm{nt}^{\mathrm{R}} / 36 \mathrm{nt}$ primer template complexes by Pol $\beta$ and $\mathrm{KF}(\mathrm{exo}-)$.

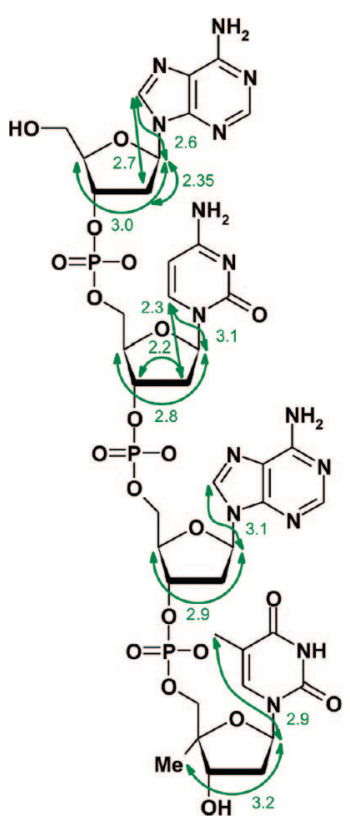

\begin{tabular}{|c|c|c|}
\hline ROE & $\begin{array}{l}\text { Experimental } \\
\text { distances }[\AA ̊]\end{array}$ & $\begin{array}{l}\text { Sequential ROEs in } \\
\text { B-DNA (C26-endo, } \\
\text { anti) }[\AA]]\end{array}$ \\
\hline $\mathrm{H} 2^{\prime} \mathrm{a}-\mathrm{H} 5 \mathrm{~b}$ & 3.55 & 3.6 \\
\hline H2“a $a-H 5 b$ & 4.1 & 2.7 \\
\hline H2“a & 3.2 & 2.2 \\
\hline $\mathrm{H} 2^{\circ} \mathrm{b}-\mathrm{H} 8 \mathrm{c}$ & 3.9 & 3.8 \\
\hline $\mathrm{H2}$ "'b - H8c & 3.4 & 2.1 \\
\hline $\mathrm{H} 3^{\circ} \mathrm{b}-\mathrm{H} 8 \mathrm{c}$ & 3.3 & 4.6 \\
\hline $\mathrm{H} 1^{\prime} \mathrm{c}-\mathrm{H} 7 \mathrm{~d}(\mathrm{Me})$ & 4.0 & $>4.5$ \\
\hline $\mathrm{H}^{6} \mathrm{c}-\mathrm{H} 7 \mathrm{~d}(\mathrm{Me})$ & 3.2 & $>4.5$ \\
\hline $\mathrm{H} 4^{\prime} \mathrm{c}-\mathrm{H} 7 \mathrm{~d}(\mathrm{Me})$ & 3.8 & $>4.5$ \\
\hline $\mathrm{H} 8 \mathrm{c}-\mathrm{H} 7 \mathrm{~d}(\mathrm{Me})$ & 3.7 & 3.8 \\
\hline
\end{tabular}

Figure 6. Average ROE-derived distances within nucleotides a, b, c, and d of 4PM (green arrows) identify the syn/anti ratio and the ring puckering. Sequential ROEs between neighboring nucleotides of $\mathbf{4 P M}$ are listed in the table together with the average interproton distances of $\mathrm{C} 2^{\prime}$-endo ring puckers of B-DNA. Bold values highlight significant differences between 4PM and the values expected for idealized B-DNA.

equilibriums, NMR spectroscopy can identify local properties like ring puckering or the syn/anti equilibriums of bases as well as global changes like the melting temperature of doublestranded DNA. Here, we performed for the first time structural analysis of a 4'-methylated nucleotide incorporated in an oligonucleotide and in the presence of the complementary strand. Two complementary tetrameric DNA strands in the same sequence context were chosen as structural model for the dynamic behavior of the fraying ends of a DNA double-strand. We synthesized and compared a $4^{\prime}$-methylated oligonucleotide $\mathrm{dACAT}^{\mathrm{Me}}$ (4PM), with its unmodified counterpart 4PH with and without the complementary strand, respectively. All signal assignments are based on homo- and heteronuclear NMR spectra. By rotating-frame NOEs (ROEs), neighboring nucleotides were identified, which allowed sequential analysis. Additionally, time-averaged interproton distances were obtained according to Wüthrich. ${ }^{19}$ First, the single strands $\mathbf{4 P H}$ and $\mathbf{4 P M}$ were investigated (Figure 6). Deoxyriboses adopt mainly 2'endo puckering and are averaged in syn/anti equilibria except

(19) Wüthrich, K. NMR of Proteins and Nucleic Acids; J. Wiley \& Sons: New York, 1986; pp 220-222. for the $5^{\prime}$-terminal adenosine, which is found in the synorientation. Thus, $4^{\prime}$-methylation neither significantly alters the ring puckering or the base orientation of the nucleotide itself nor does it influence the conformational behavior of neighboring nucleotides in single-stranded DNA.

Addition of the complementary strand $4 \mathrm{~T}$ to $4 \mathrm{PH}$ and $4 \mathrm{PM}$, respectively, identified the differences and similarities in the pairing behavior of the oligonucleotides. In both cases, the same nucleobase protons experience chemical shift differences, but there was no detectable influence of $4^{\prime}$-alkylation on the complementary oligonucleotide. Chemical shift variations of both adenines of 4PM are explained by minimal variations of the base orientations, yet too small to result in variations of the ROE pattern at $300 \mathrm{~K}$, and an overlay of the ROESY spectra of $\mathbf{4 P M}$ and $\mathbf{4 P H}$ shows only minimal differences (Figure 7, Table 3). As for the single strands, the syn/anti equilibrium of the nucleobases contributed significantly to time-averaging of ROEs. The temperature dependence of the mixtures 4T/4PH and 4T/4PM, respectively, between 275 and $300 \mathrm{~K}$ showed duplex formation over a wide temperature range (data not shown). Both minimal DNA 4PH and 4PM exhibit nearly the 


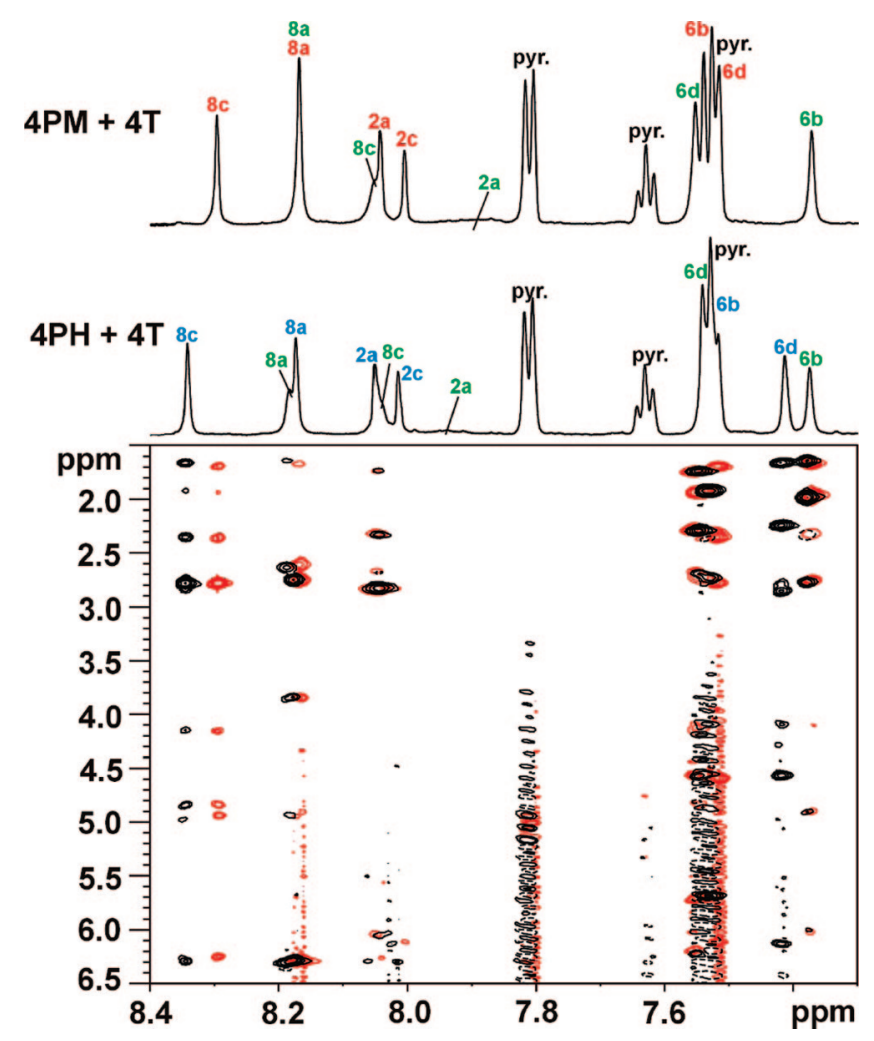

Figure 7. ROESY expansion (600 MHz, $277 \mathrm{~K}$ ) for the base resonances of $\mathbf{4 P H} / 4 \mathrm{~T}$ and $\mathbf{4 P M} / \mathbf{4 T}$ together with the ${ }^{1} \mathrm{H}$ NMR projections.

same behavior in the presence of the complementary strand 4T, and there is again, as already described for the single strands, no detectable influence of $4^{\prime}$-methylation on the $J$ coupling pattern. Yet, differences of up to $0.5 \AA$ are observed for the average ROE distances between sugar protons and the nucleobase for all four nucleotides. This can be explained by variations of the syn/anti equilibria. While the $3^{\prime}$-terminal nucleotide of 4PH and 4PM, which is the site of $4^{\prime}$-methylation, exhibits similar averaged ROEs due to the syn/anti equilibriums of the nucleobase, the neighboring adenine syn/anti equilibrium is slightly shifted toward syn in 4PM. In conclusion, the overall influence of $4^{\prime}$-methylation on the conformational equilibrium of oligonucleotides is surprisingly small.

\section{Discussion}

Our kinetic investigations of $\mathrm{Pol} \beta$ and $\mathrm{KF}$ (exo-) indicate considerably different steric constraints, which act on the sugar backbone of the incoming nucleotide within the active site and the $3^{\prime}$-end of the primer strand. In all cases, the major effects

Table 3. ${ }^{3} \mathrm{JHH}_{\mathrm{HH}}$ Coupling within the Deoxyribose Rings of 4PH and 4PM Bound to the Complementary DNA Strand

\begin{tabular}{|c|c|c|c|c|c|}
\hline \multicolumn{6}{|c|}{${ }^{3} J_{\mathrm{HH}}[\mathrm{Hz}]$} \\
\hline & $4 \mathrm{PH}$ & 4PM & & $4 \mathrm{PH}$ & 4PM \\
\hline a-ring & & & b-ring & & \\
\hline $\mathrm{H} 1^{\prime}-\mathrm{H} 2^{\prime}$ & 8 & 8 & $\mathrm{H} 1^{\prime}-\mathrm{H} 2^{\prime}$ & 8 & 8 \\
\hline $\mathrm{H} 1^{\prime}-\mathrm{H} 2^{\prime \prime}$ & 6 & 6 & $\mathrm{H} 1^{\prime}-\mathrm{H} 2^{\prime \prime}$ & 6 & 6 \\
\hline $\mathrm{H} 2^{\prime}-\mathrm{H} 3^{\prime}$ & 6 & 6 & $\mathrm{H} 2^{\prime}-\mathrm{H} 3^{\prime}$ & 6 & 6 \\
\hline $\mathrm{H} 2^{\prime \prime}-\mathrm{H} 3^{\prime}$ & 3 & 3 & $\mathrm{H} 2^{\prime \prime}-\mathrm{H} 3^{\prime}$ & 3 & 2 \\
\hline $\mathrm{H} 3^{\prime}-\mathrm{H} 4^{\prime}$ & 3 & 3 & $\mathrm{H} 3^{\prime}-\mathrm{H} 4^{\prime}$ & 3 & 3 \\
\hline c-ring & & & d-ring & & \\
\hline $\mathrm{H} 1^{\prime}-\mathrm{H} 2^{\prime} / \mathrm{H} 2^{\prime \prime}$ & $6 / 7.5$ & $7 / 7$ & $\mathrm{H} 1^{\prime}-\mathrm{H} 2^{\prime} / \mathrm{H} 2^{\prime \prime}$ & $7 / 7$ & $6.5 / 6.5$ \\
\hline $\mathrm{H} 2^{\prime} / \mathrm{H}^{\prime \prime}{ }^{\prime \prime}-\mathrm{H} 3^{\prime}$ & $3 / 6$ & 3/n.d. & $\mathrm{H} 2^{\prime} / \mathrm{H} 2^{\prime \prime}-\mathrm{H} 3^{\prime}$ & $-/ 6.5$ & $-/ 7$ \\
\hline $\mathrm{H} 3^{\prime}-\mathrm{H} 4^{\prime}$ & 3 & 3 & $\mathrm{H} 3^{\prime}-\mathrm{H} 4^{\prime}$ & 4 & \\
\hline
\end{tabular}

of alkyl substitutions were found in the $k_{\text {pol }}$ term and only to a lesser extent in the $K_{\mathrm{d}}$ term. This indicates that the steps leading to nucleotide incorporation (e.g., conformational enzyme changes and/or phosphodiester bond formation) are more affected by size augmentation than the initial binding step. Interestingly, in case of two DNA polymerases investigated, the effects on reactivity by size augmented nucleotides are directly opposed (Figure 5). Albeit size augmentation by $4^{\prime}$-alkylation of the nucleoside triphosphate substrate affects incorporation efficiency of both enzymes, the effects on $\operatorname{Pol} \beta$ are significantly more pronounced as compared to $\mathrm{KF}$ (exo-). In particular, expanding the size by one additional methylene group from 4'-methylation to $4^{\prime}$-ethylation is well tolerated by $\mathrm{KF}(\mathrm{exo}-)$ and resulted only in a further 2-fold reduction of incorporation efficiency, while the larger nucleotide was no substrate for $\operatorname{Pol} \beta$. These results can be rationalized by differential steric demand of the nascent base within the active site of the two DNA polymerases.

For Pol $\beta$, crystal structures of the ternary complex (i.e., enzyme, primer template, and incoming dNTP) are available. ${ }^{11 \mathrm{a}, 12,20}$ Given that there is no structural information existing for KF(exo-) highly homologous Bacillus stearothermophilus DNA polymerase I (Bst Pol) $)^{1 \mathrm{~d}, \mathrm{~g}, \mathrm{~h}}$ is often used to correlate functional data to $\mathrm{KF}$ (exo-) structure. The available structures reveal that the deoxyribose moiety of the incoming dNTP is fully embedded within the substrate binding pockets of these DNA polymerases and is an integral part of the substrate recognition processes (Figure 8). The Bst Pol structure indicates that the sugar of the incoming dNTP has contacts with various residues, Arg615, Ile657, Glu658, and Asp830 (the corresponding residues in KF(exo-) are Arg668, Ile709, Glu710, and Asp830). Mutational studies of KF(exo-) showed that these residues affect fidelity. ${ }^{1 \mathrm{~b}, 21}$ Moreover, structural data reveal that Tyr271 and Phe272 in $\alpha$-helix M of Pol $\beta$ are located in the near proximity of the sugar moiety of the incoming nucleotide. These interactions in Pol $\beta$ have been discussed to be involved in the discrimination of mismatches as well. ${ }^{1 \mathrm{~b}}$ Thus, editing of the incoming dNTP sugar residue might provide DNA polymerases with an additional option to achieve canonical base pair formation through indirect readout of aberrant sugar conformations. Indeed, structural analysis of Bst $\mathrm{Pol}^{11 \mathrm{~h}}$ and $\mathrm{Pol} \beta^{20}$ complexed with noncanonical substrates as well as modeling studies of Pol $\beta^{22}$ suggest significantly altered protein side chain and nucleotide conformations as compared to the structures obtained from fully canonical substrates. Furthermore, it was reported in studies of related DNA polymerases that size alteration of amino acids that contact the nucleotide sugar residues may lead to altered enzyme fidelity. ${ }^{1 \mathrm{~b}, 23}$ This observation further supports the notion that at least for the investigated enzymes, the recognition of the 2'-deoxyribose unit is an integral part of DNA polymerase selectivity mechanism.

(20) (a) Pelletier, H.; Sawaya, M. R.; Kumar, A.; Wilson, S. H.; Kraut, J. Science 1994, 264, 1891. (b) Sawaya, M. R.; Prasad, P.; Wilson, S. H.; Kraut, J.; Pelletier, H. Biochemistry 1997, 36, 11205. (c) Batra, V. K.; Beard, W. A.; Shock, D. D.; Krahn, J. M.; Pedersen, L. C.; Wilson, S. H. Structure 2006, 14, 757.

(21) Minnick, D. T.; Bebenek, K.; Osheroff, W. P.; Turner, R. M., Jr.; Astatke, M.; Liu, L.; Kunkel, T. A.; Joyce, C. M. J. Biol. Chem. 1999, 274, 3067-3075.

(22) (a) Alberts, I. L.; Wang, Y; Schlick, T. J. Am. Chem. Soc. 2007, 129, 11100-10. (b) Radhakrishnan, R.; Arora, K.; Wang, Y.; Beard, W. A.; Wilson, S. H.; Schlick, T. Biochemistry 2006, 45, 15142-56. (c) Arora, K; Beard, W. A.; Wilson, S. H.; Schlick, T. Biochemistry 2005, 44, 13328-41. (d) Radhakrishnan, R.; Schlick, T. J. Am. Chem. Soc. 2005, 127, 13245-52. (e) Radhakrishnan, R.; Schlick, T. Proc. Natl. Acad. Sci. U.S.A. 2004, 101, 5970-5. 
A

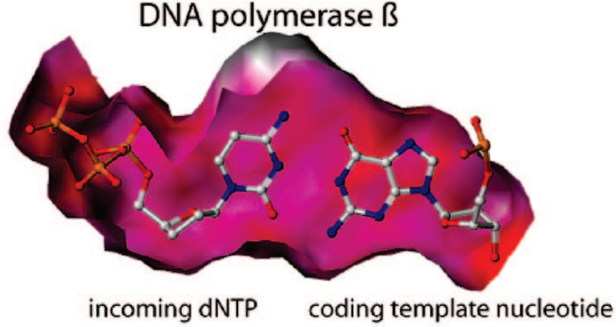

C

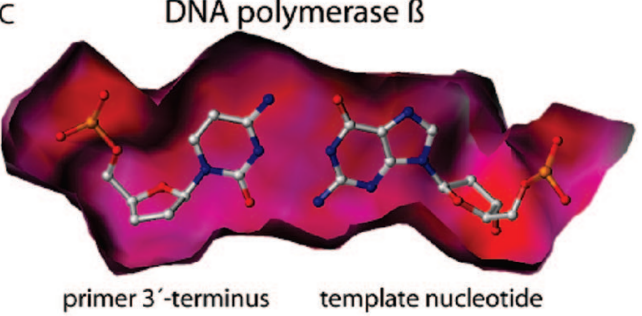

B B

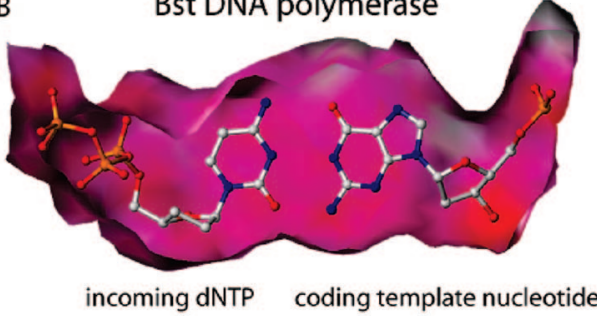

D

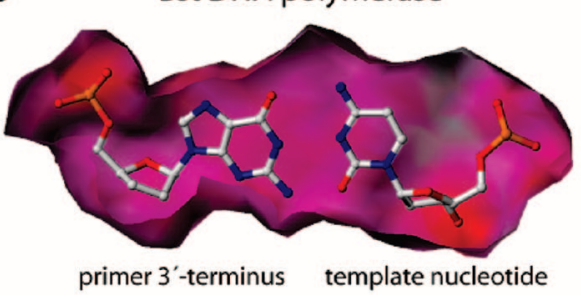

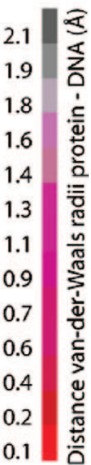

Figure 8. Graphic representations of the distances of the van der Waals radii between DNA and protein for DNA polymerase $\beta$ and Bst DNA polymerase. The separated surfaces were calculated from PDB-files (Pol $\beta, 1 \mathrm{BPY}$ and Bst, 2HVI) using Sybyl 7.2 (Tripos). View of the nascent base pair (incoming and templating nucleotides) for $\mathrm{Pol} \beta$ (A) and Bst Pol (B). Color range is given in the figure. View of the primer terminus and templating base for Pol $\beta$ (C) and Bst Pol (D).

Overall, Pol $\beta$ exhibits about 10-fold lower nucleotide insertion fidelity than $\mathrm{KF}$ (exo-), which may somewhat vary depending on assay conditions and sequence context. ${ }^{1 \mathrm{~d}, 9 \mathrm{a}, 24}$ Thus, on the basis of the concept of active site tightness, one would expect a more rigid nucleotide binding pocket in $\mathrm{KF}$ (exo-) as compared to $\operatorname{Pol} \beta$. However, our data obtained with the $4^{\prime}-$ alkylated steric probes indicate that additional size of the incoming nucleotide is somewhat better accepted (by a factor of $\sim 5)$ by the active site of $\mathrm{KF}($ exo-). This indicates more flexible interactions of $\mathrm{KF}$ (exo-) with the sugar residue of the incoming nucleotide as compared to $\mathrm{Pol} \beta$. Thus, the higher nucleotide insertion fidelity of $\mathrm{KF}$ (exo-) as compared to $\mathrm{Pol} \beta$ might derive by tighter protein interactions acting on the nucleobase rather than the sugar moiety of the incoming nucleotide, and nucleobase interactions may contribute to nucleotide insertion fidelity to a greater extent in $\mathrm{KF}$ (exo-) than in $\mathrm{Pol} \beta$. Recent experiments in which steric constraints in nucleobase recognition in the active site of $\mathrm{KF}($ exo-) were probed by employment of nucleobase surrogates that gradually expand in steric demand highlight the importance of tight nucleobase fitting to the active site of $\mathrm{KF}$ (exo-). ${ }^{7}$ It was found that the enzyme's catalytic proficiency as well as fidelity was sensitive to subtle size changes of the nucleobase. However, no such studies concerning Pol $\beta$ have been reported yet.

When investigating contacts of the enzymes with the 3 terminal nucleotide of the primer strand, we found that the efficiencies of both polymerases to extend from $4^{\prime}$-alkylated nucleotide differ by several orders of magnitude. While size augmentation by $4^{\prime}$-methylation or $4^{\prime}$-ethylation resulted in a 10 - and 15-fold decrease in extension efficiency for Pol $\beta, 7000$ and 260000 -fold reductions were observed for KF(exo-). To exclude that the pronounced effect of $4^{\prime}$-alkylation is due to aberrant conformations caused by the modification itself, which

(23) (a) Minnick, D. T.; Liu, L.; Grindley, N. D. F.; Kunkel, T. A.; Joyce, C. M. Proc. Natl. Acad. Sci. U.S.A. 2002, 99, 1194. (b) Patel, P. J.; Kawate, H.; Adman, E.; Ashbach, M.; Loeb, L. A. J. Biol. Chem. 2001, 276, 5044. (c) Shinkai, A.; Patel, P. H.; Loeb, L. A. J. Biol. Chem. 2001, 276, 18836. (d) Li, S. X.; Vaccaro, J. A.; Sweasy, J. B. Biochemistry 1999, 38, 4800.

(24) Kunkel, T. A.; Alexander, P. S. J. Biol. Chem. 1986, 261, 160-166. might affect enzyme processing in a different way, we conducted NMR investigations to analyze the inherent properties of oligonucleotides bearing 4'-alkylated nucleotides at the $3^{\prime}$ terminus. Little, if any, effect of this chemical modification on oligonucleotide conformation was found. This indicates that for the observed effects size augmentation of the analogues presumably plays the most important role. Crystal structures of Bst $\mathrm{Pol}^{11 \mathrm{~d}, \mathrm{~g}, \mathrm{~h}}$ and $\mathrm{Pol} \beta^{20}$ in complex with DNA and dNTP substrates show that both enzymes strongly interact with the 3 '-terminal nucleotide of the primer strand. These interactions take place with the sugar-phosphate backbone as well as with the nucleobase (Figure 8). Such interactions were discussed to play important roles in mismatch extension and misalignment fidelity. ${ }^{1 \mathrm{~b}}$ Enzymes exhibiting high selectivity are expected to form rigid, nonflexible interactions tolerating fewer deviations, while less selective enzymes are more flexible and may accommodate conformations that allow altered geometries without loosing activity. Perturbation of enzyme substrate interactions by size augmentation at the $3^{\prime}$-terminal primer nucleotide was significantly better tolerated by $\operatorname{Pol} \beta$ than by $\mathrm{KF}$ (exo-). While $\mathrm{Pol} \beta$ tolerates size alterations at this position, even subtle size alterations result in a significant drop of $\mathrm{KF}\left(\right.$ exo-) catalytic efficiency. The Bst Pol structures ${ }^{11 \mathrm{~d}, \mathrm{~g}, \mathrm{~h}}$ as models for $\mathrm{KF}\left(\right.$ exo-) suggest close proximity of the sugar $4^{\prime}$ position to amino acid residues located in the turn of motif $\mathrm{C}$, Val828 and His829 (880 and 881 in KF(exo-), respectively). Both amino acids are located directly nearby the catalytically essential Asp830 (882 in KF(exo-)). Additionally, mutational studies indicate that motif $\mathrm{C}$ is important for selectivity. ${ }^{14 a, 21,25}$ It is conceivable that any perturbation at this position (i.e., through size augmentation of the 3 '-terminal nucleotide in the primer strand) results in catalytically less proficient enzyme conformations, which in turn causes significantly reduced extension efficiency as observed in our study. In contrast, structures of Pol $\beta$ suggest a different topology in the near proximity of the sugar $4^{\prime}$-position. The palm domain, which contains $\beta$-sheet 5 composed of amino acids Arg253-Pro261,

(25) Strerath, M.; Gloeckner, C.; Liu, D.; Schnur, A.; Marx, A. ChemBioChem 2007, 8, 395-401. 
contacts the primer end in the minor groove. Arg254 and Asp256 mainly mediate these contacts, which are involved in nucleotidyl transfer. Evidently, our studies indicate that such an enzyme configuration in $\operatorname{Pol} \beta$ is able to accommodate perturbation of substrate interactions significantly better than the one in $\mathrm{KF}$ (exo-). With respect to the underlying mechanisms of misalignment fidelity, one would expect that $\operatorname{Pol} \beta$ is superior to $\mathrm{KF}(\mathrm{exo}-)$ in processing noncanonical substrates and thus exhibits a decreased misalignment fidelity. In fact, this kind of behavior was found as reported earlier by functional investigations of Pol $\beta$ and $\mathrm{KF}\left(\right.$ exo-). ${ }^{9}$ Our results provide first experimental evidence that indeed varied steric constraints act on the 3'-terminal primer nucleotides in both DNA polymerases.

Taken together, for the two polymerases analyzed, $\operatorname{Pol} \beta$ and $\mathrm{KF}($ exo-), we find different steric constraints preferentially acting either on the nucleoside sugar backbone within the active site or on the primer strand. For $\operatorname{Pol} \beta$, most significant steric effects were found to act on the incoming dNTP, whereas for KF(exo-) primer strand interactions are significantly more pronounced. These findings are in excellent agreement with experimentally derived data concerning the differences in fidelity such as processing of misaligned DNA substrates that cause deletions or insertions and ultimately frameshift mutations. In conclusion, the results presented provide direct evidence for the involvement of considerably varied steric effects on fidelity among different DNA polymerases.

Acknowledgment. We gratefully acknowledge financial support by the Deutsche Forschungsgemeinschaft. 